\title{
Interpreting agreement: Evidence from Japanese object honorifics
}

\author{
Shiori Ikawa*
}

\begin{abstract}
Agree is commonly considered to have no semantic effects (Chomsky 2000, 2001 a.o.). However, based on the behaviors of the Japanese object honorific $(\mathrm{OH})$ construction, this work claims that Agree can affect interpretation in such a way that its result feeds a semantic predicate. This claim is based on two observations regarding $\mathrm{OH}$. First, I examine a theoretically overlooked observation that $\mathrm{OH}$ is felicitous only when the object referent is honored by the subject referent as well as the speaker. I show that this observation suggests that the head responsible for the $\mathrm{OH}$ marking induces the interpretation that the subject and the speaker honor the object. Second, I examine the distribution of the honoree in $\mathrm{OH}$ and argue that the head responsible for $\mathrm{OH}$ marking accesses the object via Agree, in line with previous theoretical studies (Niinuma 2003; Boeckx \& Niinuma 2004). I account for both observations by proposing that the honorific head serves as a semantic predicate honor, which finds its arguments via Agree.
\end{abstract}

Keywords. object honorifics; Agree; LF-interpretability; syntax; syntax-semantics interface

1. Introduction. The object honorific $(\mathrm{OH})$ construction in Japanese is used when the object refers to an honored person from the speaker's viewpoint. For example, OH construction can be used in (1a), where the object refers to an entity honored by the speaker, the manager. In contrast, the non-honorific form must be used in (1b), where the object is Hanako, who is the speaker's friend and hence not in a position to be honored by the speaker. As seen from the contrast in (1), the predicate of the $\mathrm{OH}$ sentence is marked with the prefix $o$ or $g o$ and the light verb sur. That is, the honorific property of the object determines the predicate form, which is similar to what happens in object $\phi$-agreement in various other languages.
a. Taroo-wa butyoo-o o-tasuke-si-ta.
Taroo-TOP manager-ACC HON.PREF-help-do-PAST
"Taroo helped $(\mathrm{OH})$ the manager"
b. Taroo-wa Hanako-o tasuke-ta
Taroo-TOP Hanako-ACC help-PAST
'Taroo helped (NH) Hanako'

Some previous studies have in fact considered $\mathrm{OH}$ to be a kind of agreement: the probe around $v$ probes downward to agree with the closest animate NP in terms of honorificity (Toribio 1990; Boeckx \& Niinuma 2004; Hasegawa 2017; Ikawa \& Yamada 2020). More specifically, it has been assumed that the NPs are equipped with honorificity-related features, such as [HON: \pm ]. The honorificity feature is assigned by the speaker, reflecting the speaker's viewpoint. A functional head around the predicate is equipped with an unvalued version of those features, probes for a valued honorificity feature, and agrees with the object to be valued by it, as represented in (2).

\footnotetext{
* I would like to thank Mark Baker and Troy Messick for their comments and suggestions on the ideas in this paper. I also thank Yimei Xiang for her valuable advice. I greatly benefited from the discussions with Hazel Mitchley, Akitaka Yamada and the participants of the St@r meetings. All remaining errors are my own. Author: Shiori Ikawa, Rutgers University (shiori.ikawa@ rutgers.edu).
} 
However, while ignored by the previous syntactic works, even if the object refers to an entity honored by the speaker, $\mathrm{OH}$ marking is not allowed in examples where the subject has a higher social status than the object (Kikuchi 1994; Moriyama 1996). The unacceptability of $\mathrm{OH}$ marking in (3a) in contrast with the acceptability of (1a) above shows this point: even if the speaker is in a position to honor the manager, the use of $\mathrm{OH}$ marking is infelicitous in (3a), given that the subject referent, the CEO, has a higher status than the manager. As will be discussed in detail below, this example indicates that the subject, as well as the speaker, has to honor the object for the acceptable use of $\mathrm{OH}$.
a. \#syatyoo-wa butyoo-o o-tasuke-si-ta
CEO-TOP manager-ACC HON.PREF-help-do-PAST
"The CEO helped $(\mathrm{OH})$ the manager"
b. syatyoo-wa butyoo-o tasuke-ta / o-tasuke-ni-nar-ta
CEO-TOP manager-ACC help-PAST / help.SH-PAST
"The CEO helped (NH/SH) the manager"

Note that, this does not mean that the speaker simply identifies himself/herself with the subject in assigning the honorificity feature to the object. The example in (4), where the subject has a lower status than the object, is infelicitous when uttered by a CEO who is not in a position to honor the manager. This indicates that the $\mathrm{OH}$ sentences express the subject's honor to the object in addition to the speaker's own honor to the object.

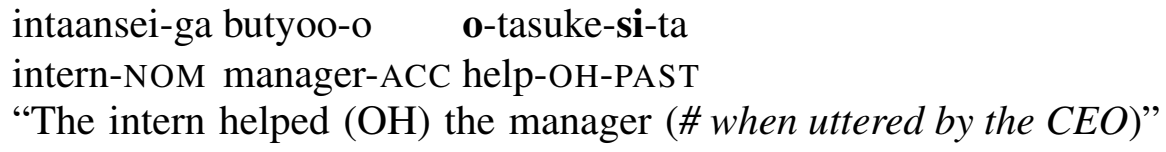

This paper aims to account for the effect of the subject on the felicity of $\mathrm{OH}$ construction. Based on this effect, I propose that the syntactic operation Agree can feed arguments to some semantic predicates. That is, I claim that the result of Agree can affect interpretation in line with some other studies (Hicks 2009; Baker \& Camargo-Souza 2020 a.o.), but in contrast with the standard assumption that Agree is devoid of any semantic effects (Chomsky 2000, 2001 a.o.). In Section 2, I show that the cause of the infelicity of $\mathrm{OH}$ marking in (3a) is the lack of honor from the subject. That is, for the $\mathrm{OH}$ use to be felicitous, there must be a semantic honor relationship between the subject and the object. In Section 3, however, I show old and new evidence that the previous studies were correct in assuming operation Agree to be involved in $\mathrm{OH}$ marking. More specifically, the honoree is always the NP that is in a goal position for the probe from around $v$. In Section 4, I account for these observations by arguing that the $\mathrm{OH}$ marker is semantically a predicate that denotes the honor-relationship between the subject + the speaker and the object, but accesses the subject and the object via Agree.

2. Semantic honor relationship. In (1a) and (3a), I showed that $\mathrm{OH}$ marking is not acceptable when the subject has a higher status than the object and suggested that the subject has to honor the object for $\mathrm{OH}$ marking to be felicitous. However, we have to be careful in determining the exact conditions for the use of $\mathrm{OH}$ regarding the subject. In addition to the possibility that the subject honor from the subject toward the object is a necessary condition for $\mathrm{OH}$ 
marking, there is an alternative possibility that the subject is required to be less honored than the object by the speaker for $\mathrm{OH}$ marking to be possible: that is, there is a possibility that between the subject and the object, the predicate simply marks honor toward the NP which is more honored by the speaker. This alternative seems compelling given that there are agreement phenomena in various other languages where the subject and the object are compared over certain hierarchies, such as person hierarchy, and the predicate exhibits agreement with the one higher in the relevant hierarchy (Béjar \& Rezac 2009; Oxford 2019 a.o.).

The unacceptability of (5)-(6) supports the view that the subject has to honor the object for felicitous $\mathrm{OH}$ use. These examples distinguish the two hypotheses from each other: the subjects refer to a criminal or a bad guy considered to have a lower social status than sensei 'professor / teacher' in a natural context. However, the sentence content makes it clear that the subject referents themselves do not honor the object referents. Under the view that the more honored one between the subject and the object should trigger the honorific marking, $\mathrm{OH}$ is incorrectly predicted to be acceptable in these examples, given that the subject referents are less honored by the speaker compared to the object. In contrast, the view that the subject needs to honor the object for the use of $\mathrm{OH}$ correctly predicts that $\mathrm{OH}$ markings are not acceptable in these examples. Thus, the unacceptability of (5)-(6) support the view that the subject has to honor the object for $\mathrm{OH}$ use to be acceptable.
\#hannin-wa
sensei-ni
kyoohakuzyoo-o
o-okuri-si-ta
criminal-TOP professor-DAT threatening.note-ACC HON.PREF-send-do-PAST

"The criminal sent $(\mathrm{OH})$ a threatening note to the professor"

(Kikuchi 1994:259)

(6) \#huryoo-ga sensei-o senkoo-to o-yobi-si-teir-u

bad.guys-NOM teacher-ACC senkoo-as HON.PREF-call-do-ASP-PRES

'The bad guys are calling $(\mathrm{OH})$ the teacher 'senkoo' (a derogatory word to refer to a teacher)'

This observation suggests that what matters in the licensing of Japanese $\mathrm{OH}$ marking is the existence of honor from the subject toward the object, in addition to the existence of honor from the speaker toward the object. In other words, it seems that $\mathrm{OH}$ construction involves a semantic predicate honor, whose honorer role is assigned to the speaker and the subject and whose honoree role is assigned to the object. Such an effect is not straightforwardly predicted by the view from the previous studies that $\mathrm{OH}$ marking is agreement with the honorificity feature on the object (Boeckx \& Niinuma 2004; Oseki \& Tagawa 2019; Ikawa \& Yamada 2020). Then, does this observation indicate that the $\mathrm{OH}$ marking should be solely semantically treated instead, as has been attempted in some other studies (Potts \& Kawahara 2004; Watanabe et al. 2014; McCready 2019)? In the next section, however, I will show that there is also evidence indicating the involvement of the syntactic operation Agree.

3. Agree chooses the honoree. Evidence for the involvement of Agree comes from the distribution of the honoree in $\mathrm{OH}$ sentences. When the $\mathrm{OH}$ marking appears on a sentence with multiple NPs around the object position, for example a ditransitive sentence, it has to be determined which NP can serve as the honoree. As argued in previous studies (Niinuma 2003; Boeckx \& Niinuma 2004; Ikawa \& Yamada 2020), the distribution of the honoree NP is similar to the distribution of the goal NP of the object $\phi$-agreement across languages. More specifically, I show that the NP that can be the honoree in an $\mathrm{OH}$ sentence is the highest animate 
NP below $v$ in the same phase. This distribution naturally follows if the head that is responsible for the $\mathrm{OH}$ probes down for an animate $\mathrm{NP}$, and the probe is restricted by the intervention condition (or relativized locality more generally) and phase boundaries, as Agree is usually assumed to be (Chomsky 2000, 2001; Baker 2008 a.o.). In this section, I review the evidence from previous studies and add new pieces of evidence for this view.

Before a detailed analysis, some clarifications regarding the theoretical assumptions are in order. First, as for the intervention condition on Agree, I adopt the view that not only the c-commanding intervener but also the "A-over-A" intervener counts (Rackowski \& Richards 2005; Niinuma 2003). Second, I adopt the view from Ikawa \& Yamada (2020) that the head responsible for $\mathrm{OH}$ marking is distinct from $v$. More specifically, I follow Ikawa \& Yamada (2020) in positing a head HON right below $v$ and considering that the probe is on HON.

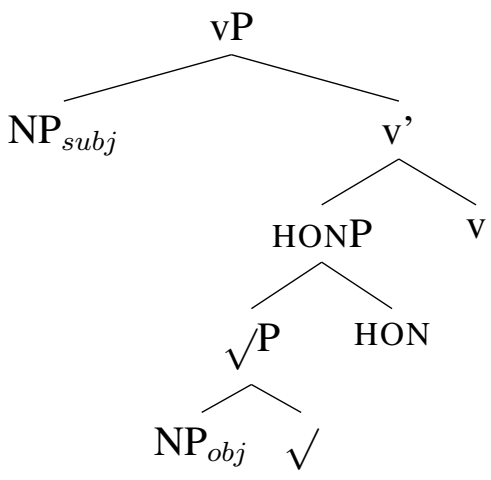

First, I will review evidence from previous studies for the view that Agree is involved in the choice of honoree: the intervention effect in ditransitive sentences and the intervention effect inside NPs. Then, I will further add two new pieces of evidence for this view: the lack of intervention patterns in appropriate structures and the phase effect.

3.1. INTERVENTION IN THE DITRANSITVE SENTENCES. First, in ditransitive constructions with two animate objects, it has long been noticed that the honoree is always the indirect object (IO) and not the direct object (DO) (Harada, 1976; Niinuma, 2003; Boeckx \& Niinuma, 2004 a.o.): In (8), $\mathrm{OH}$ is felicitous when the honored entity sensei is the IO and not the DO.
a.
Hanako-ga sensei-ni
Taroo-o go-syookai-si-ta
Hanako-NOM professor-DAT Taroo-ACC go-introduce-LV-PAST
"Hanako introduced (OH targeting Prof) Taroo to the professor"
b. Hanako-ga Taroo-ni sensei-o syookai-si-ta/\#go-syookai-si-ta Hanako-NOM Taroo-DAT professor-ACC introduce-PAST/go-introduce-LV-PAST "Hanako introduced (\#OH targeting Prof) professor to Taroo"

Empirically, this pattern parallels the choice of the trigger of object $\phi$-agreement (Baker 2008, 2013 a.o.), as Niinuma (2003); Boeckx \& Niinuma (2004) point out. For instance, in the example in (9) from Swahili, the predicate can agree with the IO mtoto 'child' (class 1), but cannot agree with the DO kitabu 'book' (class 7).
Stella a-li-m-pa
/ *a-li-ki-pa
mtoto kitabu pale
1.Stella SM1-PAST-OM1-give / SM1-PAST-OM7-give 1.child 7.book 16.there

'Stella gave the child a book there'

(Riedel 2009:131) 
Theoretically, this pattern follows from the idea that Agree is involved in the choice of honoree. Under the assumption that the IO is generated higher than the DO as shown in (10) (Hoji 1985; Hayashishita 2000, 2004; Kishimoto 2008), IO is closer to the probe around $v$ than the DO is. Given that the probe has to agree with the closest NP it finds (intervention condition), the IO but not the DO can be found by the head HON.

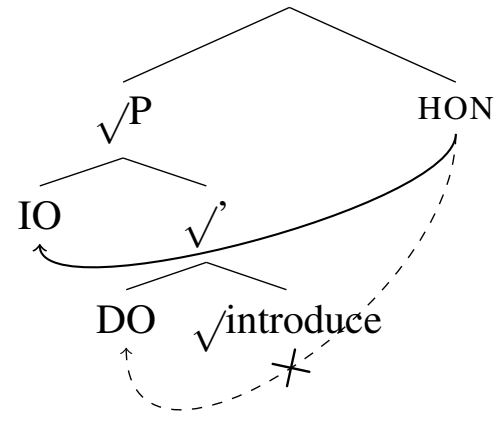

Note that the intervention effect in $\mathrm{OH}$ is reported to be sensitive only to animate NPs, not to inanimate NPs (Niinuma 2003). As shown in (11), the direct object Tanaka.sensei 'Prof.Tanaka' can serve as the honoree when the IO is inanimate.

Watasi-wa kaizyoo-ni Tanaka.sensei-o o-ture-si-ta
1sg.-TOP place-DAT Prof.Tanaka-ACC HON.PREF-take-do-PAST
"I took (OH) Prof.Tanaka to the place"
(Boeckx \& Niinuma 2004:456)

This pattern follows if we consider the feature $\mathrm{F}$ that is probed in $\mathrm{OH}$ is held only by animate NPs. That is, inanimate NPs that do not have the relevant feature are invisible to the probe and hence do not intervene. I will discuss the specific nature of this feature in Section 4.

3.2. InterVEntion IN THE NP DOMAIN. Niinuma (2003) shows that, when the object NP is inanimate, $\mathrm{OH}$ can look into the object NP to let the possessor NP serve as the honoree. The sentence in (12) exemplifies this point. Given that inanimate NPs are not visible to the probe, such possessor honorification is expected under the Agree view: the possessor NP is the closest animate $N P$ to the probe, as shown in the structure in (14a). Crucially, the possessor NP inside an object cannot serve as the honoree when the possessee is animate. For example, (13) is not interpretable as expressing honor toward the professor, but is only interpreted as expressing honor toward the professor's friend. This contrast also follows from the Agree-view: Given the structure in (14b), the animate NP sensei-no rinzin 'the professor's neighbor' is closer to the probe than sensei 'professor', blocking the probe to find sensei.

watasi-wa [[[sensei]-no ie]-no tikaku]-o o-tazune-si-ta 1 sg-TOP prof-GEN house-ACC surroundings-ACC HON.PREF-visit-do-PAST 'I visited ( $\mathrm{OH})$ the professor's house's surroundings. (with honor toward the professor)'

\footnotetext{
\#watasi-wa [[[sensei]-no rinzin]-no ie]-o o-tazune-si-ta

1sg.-TOP professor-GEN neighbor-GEN house-ACC HON.PREF-visit-do-PAST

'I visited $(\mathrm{OH})$ the professor's neighbor's house.'
} 
(14)

a.

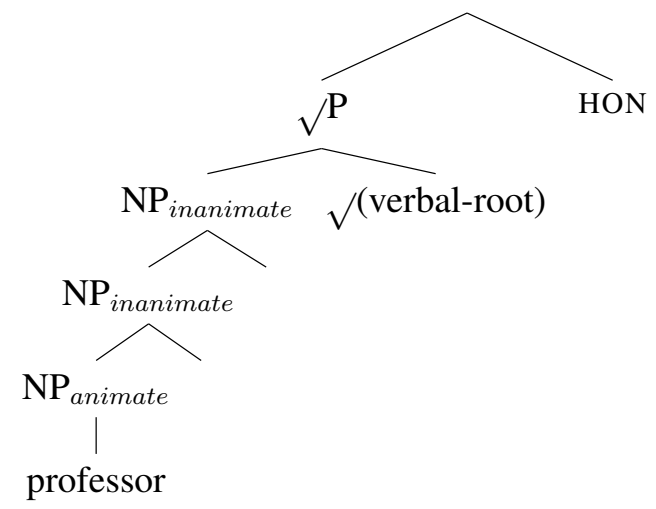

b.

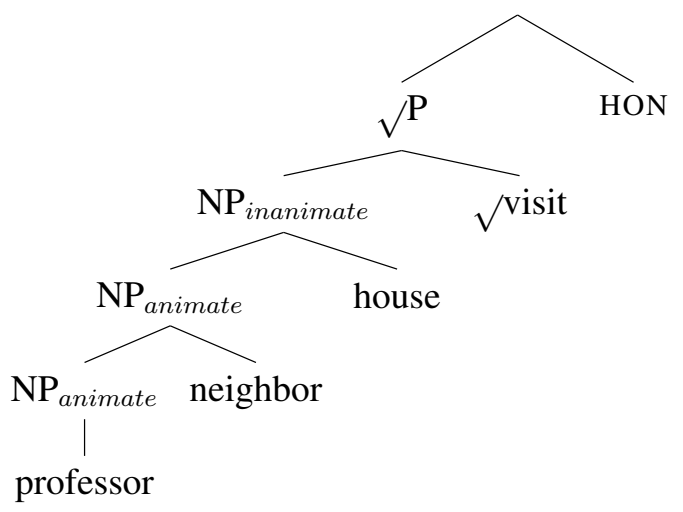

3.3. C-COMMAND EFFECT IN INTERVENTION. While previously unnoticed, the presence of a c-command relationship is crucial for the IO intervention effect. As shown above, the Agree between the $\mathrm{OH}$ probe and a DO is blocked by an animate IO. However, the examples in (15) show that when the IO itself is an inanimate NP but contains an animate NP as a possessor, either the DO or the animate possessor NP inside the IO can serve as the honoree.
a. Taroo-wa Hanako-no heya-ni sensei-o o-ture-si-ta
Taroo-TOP Hanako-GEN room-DAT professor-ACC HON.PREF-take-do-PAST
'Taroo took professor to Hanako's room'
b. Taroo-wa sensei-no heya-ni Hanako-o o-ture-si-ta
Taroo-TOP professor-GEN room-DAT Hanako-ACC HON.PREF-take-do-PAST
'Taroo took Hanako to professor's room'

The availability of the $\mathrm{DO}=$ honoree interpretation in $(15 \mathrm{a})$ is correctly predicted by the Agree analysis: as shown in (16), the IO possessor does not c-command the DO. Given that the interventions are defined based on a c-command (or dominance) relationship (Rizzi 2013 a.o.), the IO possessor does not structurally intervene between HON and DO. Thus, the possessor NP inside the IO and the DO are both potential goals for a downward probe from HON, and the Agree analysis correctly predicts the grammaticality of both (15a) and (15b). ${ }^{1}$

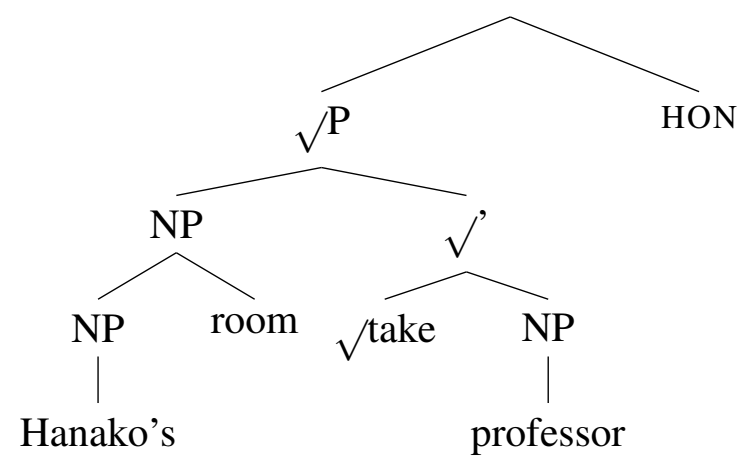

3.4. Phase EfFECT. Another piece of novel data for the Agree approach comes from the effect of phases in the choice of honoree. The example in (17) shows that the $\mathrm{OH}$ marking is sensitive to phase boundaries: $\mathrm{OH}$ marking is not available on the matrix predicate when the

${ }^{1}$ I assume that, when there are multiple potential goals for a probe, the probe can Agree with any of them. 
NP sensei 'professor' is not in the same phase, but in an embedded clause, even if it is the closest animate NP for the probe.

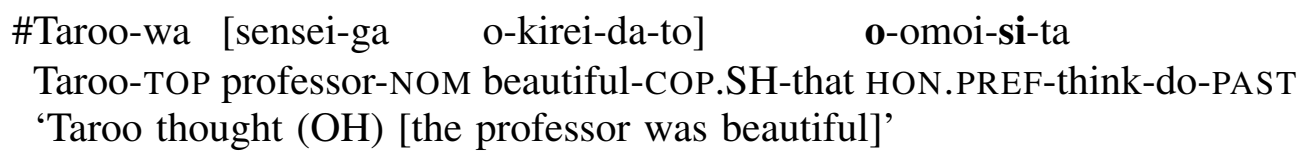

This follows from the view that the honoree in $\mathrm{OH}$ is chosen by Agree, which is considered to be phase-bounded (Chomsky 2000, 2001; Baker 2008). Given that the probe is on HON head right below the matrix $v \mathrm{P}$, as indicated in (18), the dependency between the probe and the NP sensei 'professor' in (17) crosses a phase boundary introduced by the embedded CP, violating the phase condition for Agree.

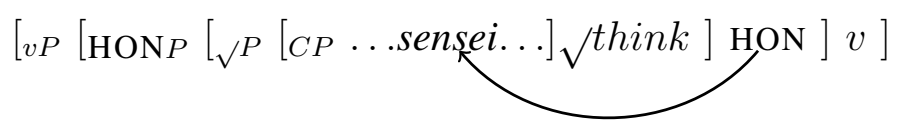

Furthermore, the use of the raising-to-object construction improves the $\mathrm{OH}$ marking. The example in (19) is the raising-to-object counterpart of (17). While I will set aside the discussion about the exact structure of raising-to-object constructions in Japanese (see Horn (2008) for a detailed discussion), the accusative marking on the embedded subject in (19) suggests that there is no phase boundary between the accusative case assigner, that is the main predicate, and the embedded subject sensei. The contrast between (17) and (19) supports the view that the unacceptability of (17) is due to the existence of the phase boundary.
?watasi-wa [sensei-o
okirei-da-to]
o-omoi-si-ta
Taroo-TOP professor-ACC beautiful-COP-that HON.PREF-think-do-PAST
'Taroo thought $(\mathrm{OH})$ the professor to be beautiful'

3.5. INTERIM SUMmARY. In this section, I have shown the data that suggests that an Agreebased analysis correctly captures the NP that can serve as the honoree. While I have shown in Section 2 that the semantic honor relationship holds between the subject and the object in $\mathrm{OH}$ sentences, the distribution of the honoree we have just seen does not straightforwardly follow from a purely semantic analysis. For example, one might propose a semantic analysis in which the $\mathrm{OH}$ marker modifies the main predicate in such a way that the "honoree" is semantically identified with a certain argument of the predicate, either by the order of semantic composition with the predicate (Watanabe et al. 2014) or by its thematic role. However, such an account has difficulty in handling the honorification of the possessor of the argument as shown in (12)-(13) above, where the NP serving as the honoree is not itself an argument of the main predicate. Second, I showed that the existence of c-commanding animate NPs is crucial in determining the possibility of DO honorification. This indicates that the syntactic operations are involved in the choice of the honoree.

Thus, $\mathrm{OH}$ exhibits both a semantic nature in its restriction on the subject-object relationship and a syntactic nature in the choice of the honoree. The next question is how these two conflicting characteristics can be analyzed. In the next section, I account for both sets of observations by proposing that Agree feeds arguments to the semantic predicate honor.

\section{Proposal.}

4.1. MAIN ANALYSIS. The discussion above suggests that, while $\mathrm{OH}$ sentences seem to express semantic honor relationships between the subject + the speaker and the object, the $\mathrm{OH}$ 
construction involves Agree in the choice of the honoree. I propose that these effects are derived by bi-directional Agree from HON in the narrow syntax with the object and the subject, and the interpretation of the results of Agree at $\mathrm{LF}^{2}$

As mentioned above, I assume that the probe lies in an optional head HON (Ikawa \& Yamada 2020). I propose that this head contains two probes: one going upward and the other going downward, as shown in (20). ${ }^{3}$ The downward probe finds the highest object. The upward probe finds the subject in the specifier of $\mathrm{vP}$ within the same phase.

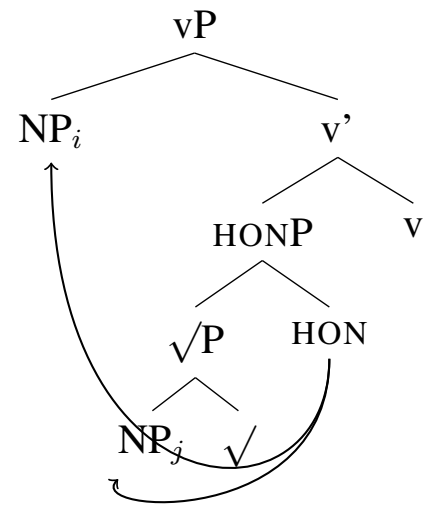

While I assume the involvement of Agree in $\mathrm{OH}$ in line with previous studies, the current analysis deviates from previous studies in NOT assuming that the probe looks for honorificityencoding features, such as [HON: \pm ]. Instead, I propose that the feature involved in Agree in $\mathrm{OH}$ is the index feature, which has been considered to participate in Agree for some other phenomena (Person Case Constraint (Adger \& Harbour 2007), plural agreement (Grosz 2015) and switch reference (Arregi \& Hanink 2018, 2019)). Thus, HON contains a pair of probing features as represented in (21a). (21a) is a combination of two unvalued but interpretable index features. ${ }^{4}$ The feature $i n t F_{1}[$ ] probes downward to be valued by the index feature of the closest animate object (or the possessors of the object), while $i n t F_{2}$ [ ] probes upward to be valued by the index feature on the subject. As a result of the Agree operation represented in (20), the probe is valued as shown in (21b). As these probing features are interpretable, they are not deleted at the spell-out and survive in LF.

$$
\begin{array}{ll}
\text { a. } & \left\langle i n t F_{1}[], i n t F_{2}[]\right\rangle \\
\text { b. } & \left\langle i n t F_{1}[j], i n t F_{2}[i]\right\rangle
\end{array}
$$

${ }^{2}$ I assume here that HON chooses the subject as an honorer via Agree as well, given that HON is not in a direct selectional relationship with the subject (i.e., is in a long-distance relationship with HON) as shown in the structure in (7). Unfortunately, for subjects, it is not easy to find a clear-cut evidence for the Agree view as we did for the object, given that there is often only one NP in the domain higher than HON. While I tentatively take the upward Agree analysis for the subject choice of the subject as an honorer in this paper, the appropriateness of the idea that the choice of the honorer involves upward Agree can and should be examined independently from the main claim of this paper that Agree feeds the semantic predicate HON: the object NP chosen by the downward Agree feeds the honoree argument of the semantic predicate honor.

${ }^{3}$ I distinguish having two separate probes on one head from the Multiple Agree mechanism proposed by Hiraiwa (2001), where a single probe agrees with multiple goals. It is the former that I propose for OH here.

${ }^{4}$ Note that the existence of unvalued interpretable features is a natural result of dissociation of interpretability and valuedness proposed in Pesetsky \& Torrego (2007). 
I propose that the head HON bears the honorific meaning in (22), referring to the nowvalued probe features on HON. More specifically, these goals, along with the speaker in the context, serve as arguments of the semantic predicate honor on HON, resulting in the interpretation that the speaker and the subject honor the object. (22) mentions that the referent of the goal of the upward probe and the speaker $S p$ together honor the referent of the goal of the downward probe. ${ }^{5}$

$$
S p \text { and } \llbracket \mathrm{NP}_{\left.i n t F_{2}[]\right]} \rrbracket \text { honor } \llbracket \mathrm{NP}_{i n t F_{1}[] \rrbracket}
$$

The Agree view from previous studies assumed that the valuation of HON affects vocabulary insertion on HON, under the assumption that the HON is valued with [ $\pm \mathrm{HON}$ ] (Niinuma 2003; Boeckx \& Niinuma 2004; Oseki \& Tagawa 2019; Ikawa \& Yamada 2020). The current proposal contrasts such a view in assuming that the HON head does not change its morphological forms depending on the valuation of its features: the presence of HON always triggers the honorific morphology including the honorific prefix $o / g o$ and the use of the light verb, regardless of how the probe features on HON are valued. That is, the valuation of the probing features does not directly affect the morphology, and it only affects the interpretation. The HON head is optional, and the use of HON and the OH morphology realizing HON are appropriate only when the honorific meaning HON adds is pragmatically felicitous.

This analysis correctly derives the observation of the effect of the subject on $\mathrm{OH}$. The core contrast is repeated in (23), with the indices added to each NP.

$$
\begin{aligned}
& \text { a. } \text { Taroo }_{i} \text {-wa } \text { butyoo }_{j} \text {-O o-tasuke-si-ta } \\
& \text { Taroo-TOP manager-ACC HON.PREF-help-do-PAST } \\
& \text { "Taroo helped (OH) the manager" } \\
& \text { b. \#syatyoo }{ }_{k} \text {-wa butyoo }{ }_{j} \text {-O o-tasuke-si-ta } \\
& \text { CEO-TOP manager-ACC HON.PREF-help-do-PAST } \\
& \text { "The CEO helped }(\mathrm{OH}) \text { the manager" }
\end{aligned}
$$

To derive (23a), as a result of Agree between HON, the probes on HON get valued as shown in (24a). Under the current analysis, these indices serve as a part of the honorific meaning of HON as represented in $(24 b)$. The resulting interpretation is "the Speaker and Taroo honor the manager," which is felicitous in a natural context.

$$
\begin{array}{ll}
\text { a. } & \left\langle i n t F_{1}[j], i n t F_{2}[i]\right\rangle \\
\text { b. } & S p \text { and } \llbracket \mathrm{NP}_{i} \rrbracket \text { honor } \llbracket \mathrm{NP}_{j} \rrbracket \\
& =S p \text { and Taroo honor the manager }
\end{array}
$$

In contrast, for the derivation of (23b), the result of Agree appears to be like (25a). This results in an interpretation given in (25b), which is infelicitous because the CEO is not in a position to honor the manager.
a. $\left\langle i n t F_{1}[j]\right.$, int $\left.F_{2}[k]\right\rangle$
b. $\quad S p$ and $\llbracket \mathrm{NP}_{k} \rrbracket$ honor $\llbracket \mathrm{NP}_{j} \rrbracket$
$=S p$ and the CEO honor the manager

\footnotetext{
${ }^{5}$ Following Potts \& Kawahara (2004) and Potts (2007), I assume the honorific meaning in (22) is an non-at-issue expressive meaning. I abstract away the details of the semantic representations of the honor relationship, as nothing in the current analysis hinges on the specific semantic representation (see Potts \& Kawahara (2004), Potts (2007), McCready (2014, 2019) and Portner et al. (2019) for detailed discussions).
} 
A non-honorific sentence as shown in (26) has a structure without the HON head and, hence, lacks any honorific morphology as well as honorific meanings held by HON. As no linguistic element adds information about honorific relationships in the structure without the HON head, the lack of $\mathrm{OH}$ marking is neutral about the honorife status of the object.

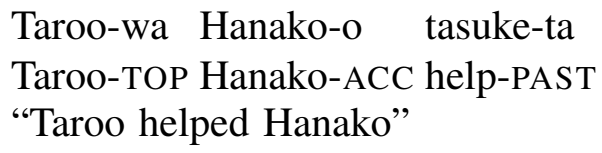

This neutrality of the non-honorific construction is empirically supported. As noted by previous studies, OH marking is optional (Namai 2000; Hasegawa 2017). That is, as exemplified in (27), the failure to use the $\mathrm{OH}$ construction for an honored object does not mean that the speaker is disrespectful toward the object. This is straightforwardly captured under the current analysis which considers the lack of $\mathrm{OH}$ marking to indicate the absence of honorific meaning.

Taroo-wa butyoo-o tasuke-ta

Taroo-TOP manager-ACC help-PAST

"Taroo helped the manager"

Given that the honoree is chosen via downward Agree, the Agree patterns in the choice of the honoree as demonstrated in Section 3, more specifically the intervention effect and the phase effect naturally follow from the current analysis. However, we need one additional assumption to account for the relativization of the probe to the animate NPs. Recall that, such relativization is evident in the examples repeated in (28), where the animate IO blocks the DO from triggering $\mathrm{OH}$ marking, while the inanimate $\mathrm{IO}$ does not.

a. Hanako-ga Mary-ni Tanaka.sensei-o

Hanako-NOM Taroo-DAT Tanaka.sensei-ACC

syookai-si-ta/\#go-syookai-si-ta

introduce-PAST/HON.PREF-introduce-do-PAST

"Hanako introduced / \#introduced $(\mathrm{OH})$ Professor Tanaka to Mary 6

(Boeckx \& Niinuma 2004:456)

b. Watasi-wa kaizyoo-ni Tanaka.sensei-o o-ture-si-ta 1sg.-TOP place-DAT Prof.Tanaka-ACC HON.PREF-take-do-PAST

"I took $(\mathrm{OH})$ Prof.Tanaka to the place"

(Boeckx \& Niinuma 2004:456)

As mentioned above, this relativization indicates that the probe looks for a feature held only by animate NPs. The current analysis does not immediately derive this relativization, as it considers the probed features as index features and it is natural to assume that index features are held by inanimate NPs, given that indices are deeply related to reference and inanimate NPs can refer. ${ }^{7}$

Instead, I propose that the probe here is relativized to the index feature paired with the person feature, which I call index-person features, and that person features are held only by

\footnotetext{
${ }^{6}$ If the $\mathrm{OH}$ construction is used, the $\mathrm{OH}$ marker is only interpretable as expressing honor towards Mary, which is pragmatically infelicitous.

${ }^{7}$ Although I assume that indices and reference are deelply related, I assume that quantified NPs can have index features as well and that the index features on the quantified NPs vary along with the variable index (See variable feature in (Hicks 2009) and binder index in (Sudo 2012) for similar ideas).
} 
animate NPs in Japanese. First, person features are considered to be held only by animate NPs at least in some languages (Lochbihler et al. 2015; Adger \& Harbour 2007). It has also been independently proposed that index features are related to person features (Wechsler \& Zlatić 2000; Sudo 2012; Podobryaev 2017). Combining these two lines of analyses, I propose that the probe on HON is relativized to the index-person features, and they are limited to animate NPs, by assuming that person features are held only by animate NPs in Japanese.

4.2. ENCODING THE HONOR RELATIONSHIP ON THE PROBE. One crucial difference between the current analysis and the previous Agree analysis lies in the position where the honorific information is grammatically encoded. In the current analysis, the meaning of honor toward the object is represented on the HON head: The HON head finds two NPs via Agree and adds the meaning "the speaker and the upper goal honor the lower goal." Here, the object itself does not have information about its honorific status. In contrast, as mentioned above, the previous Agree analysis assumes that honorificity-related features such as [HON:+] on the object NPs, not the probe, encode the object NPs' honorific status (Boeckx \& Niinuma 2004; Oseki \& Tagawa 2019; Ikawa \& Yamada 2020 a.o.).

This difference leads to a difference in predictions about the behavior of $\mathrm{OH}$ in a structure where one NP is agreed with by multiple predicates, more specifically, in raising relatives. It has been claimed that at least some relative clauses involve the raising of the same NP from the relative-clause internal position to the head noun position (Åfarli 1994; Kayne 1994; Bhatt 2002; Erlewine \& Gould 2016). Thus, in raising relatives, (the copies of) the same NP can in principle agree with the probes in two distinct clauses, that is, the probe in the relative clause and the probe in the main clause. The view that the honorificity is represented on the object NP predicts that the same NP either consistently triggers $\mathrm{OH}$ marking or consistently does not across different predicates that it agrees with: if the NP has [HON:+] and this feature triggers $\mathrm{OH}$ marking on the probe, then the NP is expected to trigger $\mathrm{OH}$ marking on every predicate that it agrees with. In contrast, if the NP has [HON:-], it will not trigger $\mathrm{OH}$ marking in any predicates it agrees with. However, the current view predicts that the same NP could trigger $\mathrm{OH}$ marking in one clause while it cannot in another clause, as the presence of $\mathrm{OH}$ marking is decided based on the honorific relationship between the NP and the subject in the clause represented in the HON head in each clause. In this section, I will show that the prediction by the current analysis is borne out.

Bhatt (2002) claims that the relative clauses have raising structures when the head noun includes a modifier like first which is interpreted in a lower position of the relative clause. (29a), for example, has an interpretation "the book which [John said that [Tolstoy has written first]]" (in contrast with the interpretation "the book which [John said first that [Tolstoy has written]]") and this interpretation can only be derived by the structure like (29b), where the head NP is raised from the lowest relative clause.
a. the first book that John said that Tolstoy has written
b. the [first book $]_{j}\left[t_{j}\right.$ that John said $\left[t_{j}\right.$ that Tolstoy has written $\left.\left.t_{j}\right]\right]$

(30) in the specified context shows a similar example in Japanese, where the sentence has the low reading of saisyo-no 'first': the person the speaker saw is someone Hanako said [John is waiting first] (not someone Hanako first said John is waiting).

(30) Context: John is waiting for several people to come one by one in a certain order. Hanako 
said that Taroo is the first person John is waiting for. The speaker saw Taroo.

watasi-wa [[John-ga mat-teiru-to] Hanako-ga it-ta] saisyo-no hito-o

(1sg-TOP) John-NOM wait-ASP-that Hanako-NOM say-PAST first-GEN person-ACC

mikake-ta

saw-PAST

'I saw the first person Hanako said John is waiting for'

Now, we can consider $\mathrm{OH}$ marking in a raising relative example as shown in (31). Similar to (30), (31) in the indicated contexts involves a low reading of the modifer saisyo-no, indicating that the relative clauses in these examples are derived by raising the NP saisyo-no senpai 'the first senior' from the relative clause internal position to the head noun position. That is, this NP agrees with both the the relative clause probe and the matrix clause probe. Now, (31a) shows that it is not possible to have $\mathrm{OH}$ marking both in the relative clause and in the main clause, as the relative clause subject sensei 'teacher' does not honor senpai 'senior', the moved NP. However, (31b) shows that it is still possible to have $\mathrm{OH}$ marking only on the matrix predicate, as the speaker, who is referred to by the matrix subject, is in a position to honor senpai 'senior'.

(31) Context: The teacher is waiting for several students to come one by one. The students are all senior to the Speaker. Hanako said that Taroo is the first senior student the teacher is waiting for. The speaker saw Taroo.

a. \#watasi-wa [[sensei-ga o-mati-si-teiru-to] Hanako-ga it-ta]

1sg-TOP teacher-NOM HON.PREF-wait-do-ASP-that Hanako-NOM say-PAST

saisyo-no senpai-o o-mikake-si-ta

first-GEN senior-NOM HON.PREF-see-do-PAST

'I saw (OH) The first senior that Hanako said the teacher is waiting for $(\mathbf{O H})$ '

b. watasi-wa [[sensei-ga mat-teiru-to/o-mati-ni-nar-teiru-to] Hanako-ga it-ta] 1sg.-TOP teacher-NOM wait-ASP-that/wait.SH-ASP-that Hanako-NOM say-PAST saisyo-no senpai-o o-mikake-si-ta first-GEN senior-ACC HON.PREF-see-do-PAST

'I saw (OH) The first senior that Hanako said the teacher is waiting for $(\mathbf{N H}) /(\mathbf{S H})$ '

This pattern is not expected under the Agree view from the previous literature: if the object NP itself is marked as honored with the feature [HON:+] and the $\mathrm{OH}$ morphology is agreement with this feature, the object NP should be able to trigger $\mathrm{OH}$ in both clauses. On the contrary, if the object NP bears [HON:-], it should not be able to trigger $\mathrm{OH}$ in either clause. The current analysis, in contrast, correctly derives this pattern. There are two possible positions for HON in this example as shown in the structure in (32): on the matrix predicate mikaker 'see' and on the predicate of the lowest relative clause mat 'wait'.

(32) I saw HON [[first senior $i]]\left[t_{i}\right.$ Hanako said $\left.\left.\left[t_{i} \text { the teacher is waiting.for HON [first senior }\right]_{i}\right]\right]$

The HON in the matrix clause, as a result of Agree with the raised NP, bears the interpretation "the speaker and I (=the speaker) honor the first senior". This statement is felicitous as the speaker has a lower status than the senior student and, hence, the $\mathrm{OH}$ marking on the matrix predicate is possible. In contrast, the HON on the lowest embedded predicate will acquire 
the interpretation "The speaker and the teacher honor the first senior." This is pragmatically infelicitous given that the teacher is not in a position to honor the students, leading to the unacceptability of $\mathrm{OH}$ marking on the embedded predicate. Thus, the current analysis not only captures the effect of subjects in $\mathrm{OH}$ as argued in Section 4.1, but also overcomes the problem inherent to the view that represents honorificity on NPs as features.

5. Conclusion. While Japanese $\mathrm{OH}$ exhibits an Agree-like pattern in the syntactic distribution of the honoree, it expresses a semantic honorific relationship between the object and the subject as well as the speaker. I have shown that this observation can be explained if the result of Agree over index-person features are fed into the semantic predicate honor on the head HON. The idea that Agree operations can interact with LF interpretations has been independently proposed by works such as Hicks (2009) and Baker \& Camargo-Souza (2020), in contrast with the common view that Agree is an operation that affects only morphology. While the current study diverges from these works by introducing a mechanism where a semantic predicate selects its argument via Agree, in a broader view, the observations and the analyses in this paper add another piece of evidence in favor of this line of research.

\section{References}

Adger, David \& Daniel Harbour. 2007. Syntax and syncretisms of the person case constraint. Syntax 10(1). 2-37. https://doi.org/10.1111/j.1467-9612.2007.00095.x.

Åfarli, Tor A. 1994. A promotion analysis of restrictive relative clauses. The Linguistic Review 11(2). 81-100. https://doi.org/10.1515/tlir.1994.11.2.81.

Arregi, Karlos \& Emily Hanink. 2018. Switch reference in Washo as multiple subject agreement. Proceedings of the North East Linguistic Society (NELS) 48. 39-48.

Arregi, Karlos \& Emily Hanink. 2019. Switch reference as index agreement. Ms. The University of Chicago.

Baker, Mark \& Livia Camargo-Souza. 2020. Agree without agreement: Switch-reference and reflexive voice in two panoan languages. Nat Lang Linguist Theory 38. 1053-1114. https://doi.org/10.1007/s11049-019-09463-w.

Baker, Mark C. 2008. The syntax of agreement and concord. Cambridge, UK: Cambridge University Press. https://doi.org/10.1017/CBO9780511619830.

Baker, Mark C. 2013. On agreement and its relationship to case: Some generative ideas and results. Lingua 130. 14-32. https://doi.org/10.1016/j.lingua.2012.03.010.

Béjar, Susana \& Milan Rezac. 2009. Cyclic agree. Linguistic Inquiry 40(1). 35-73. https://doi.org/10.1162/ling.2009.40.1.35.

Bhatt, Rajesh. 2002. The raising analysis of relative clauses: Evidence from adjectival modification. Nat Lang Seman 10. 43-90. https://doi.org/10.1023/A:1015536226396.

Boeckx, Cedric \& Fumikazu Niinuma. 2004.Conditions on agreement in Japanese. Nat Lang Linguist Theory 22(3). 453-480. https://doi.org/10.1023/b:nala.0000027669.59667.c5.

Chomsky, Noam. 2000. Minimalist inquiries: The framework. In Roger Martin, David Michaels, Juan Uriagereka \& Samuel Jay Keyser (eds.), Step by step: Essays on minimalist syntax in honor of Howard Lasnik, 89-155. Cambridge, MA: MIT press.

Chomsky, Noam. 2001. Derivation by phase. In Michael Kenstowicz (ed.), Ken Hale: A life in language. Cambridge, MA: MIT press. 
Erlewine, Michael Yoshitaka \& Isaac Gould. 2016. Unifying Japanese relative clauses: copychains and context-sensitivity. Glossa 1(1). 51. http://doi.org/10.5334/gjgl.174.

Grosz, Patrick Georg. 2015. Movement and agreement in right-node-raising constructions. Syntax 18(1). 1-38. https://doi.org/10.1111/synt.12024.

Hasegawa, Nobuko. 2017. Honorifics. In Martin Everaert \& Henk C. Van Riemsdijk (eds.), The Wiley Blackwell companion to syntax (2nd Edition), 1-51. Hoboken, NJ: Wiley-Blackwell.

Hayashishita, JR. 2000. Scope ambiguity and 'scrambling'. West Coast Conference on Formal Linguistics (WCCFL) 19. 204-217.

Hayashishita, JR. 2004. Syntactic scope and non-syntactic scope. Los Angeles: University of Southern California dissertation.

Hicks, Glyn. 2009. The derivation of anaphoric relations. Amsterdam: John Benjamins. https://doi.org/10.1075/la.139.

Hiraiwa, Ken. 2001. Multiple agree and the defective intervention constraint in japanese. MIT Working Papers in Linguistics 40(40). 67-80.

Hoji, Hajime. 1985. Logical form constraints and configurational structures in Japanese. Seattle: University of Washington dissertation.

Horn, Stephen Wright. 2008. Syntax, semantics, and pragmatics of accusative-quotative constructions in Japanese. Columbus, OH: The Ohio State University dissertation.

Ikawa, Shiori \& Akitaka Yamada. 2020. A hybrid approach to honorific agreement. Proceedings of the Chicago Linguisitc Society (CLS) 56.

Kayne, Richard S. 1994. The antisymmetry of syntax. Cambridge, MA: MIT press.

Kikuchi, Yasuto. 1994. Keigo [honorifics]. Tokyo: Kadokawa Shoten (reprinted in 1997, Tokyo: Kôdansha).

Kishimoto, Hideki. 2008. Ditransitive idioms and argument structure. Journal of East Asian Linguistics 17(2). 141-179. https://doi.org/10.1007/s10831-008-9023-y.

Lochbihler, Bethany, Will Oxford \& Nicholas Welch. 2015. The person-animacy connection: Evidence from Algonquian and Dene. Presentation at Gender, Class, and Determination: A Conference on the Nominal Spine.

McCready, Elin. 2014. A semantics for honorifics with reference to Thai. Proceedings of the Pacific Asia Conference on Language, Information and Computing 28. 503-512.

McCready, Elin. 2019. The semantics and pragmatics of honorification. Oxford, UK: Oxford University Press. https://doi.org/10.1093/oso/9780198821366.001.0001.

Moriyama, Yukiko. 1996. Nihongo keigo hyoogen no siteki tenkai nituite no kenkyuu-sonsya teii zyuusi no keigo kara ziko teii zyuusi no keigo e [research on the historical change of jpaanaese honorifics-from the honorifics focusing on the position of the target of honorifics to the honorifics focusing on the position of self]: Nara, JP: Nara Women's University dissertation.

Namai, Kenichi. 2000. Subject honorification in Japanese. Linguistic Inquiry 31(1). 170-176. https://doi.org/10.1162/ling.2000.31.1.170.

Niinuma, Fumikazu. 2003. The syntax of honorification: Storrs, CT: University of Connecticut dissertation.

Oseki, Yohei \& Takumi Tagawa. 2019. Dual suppletion in Japanese. Proceedings of the Workshop on Altaic Formal Linguistics 15. 193-204.

Oxford, Will. 2019. Inverse marking and Multiple Agree in Algonquin. Nat Lang Linguist Theory 37(3). 955-996. https://doi.org/10.1007/s11049-018-9428-X. 
Podobryaev, Alexander. 2017. Three routes to person indexicality. Nat Lang Semantics 25(4). 329354. https://doi.org/10.1007/s11050-017-9138-7.

Portner, Paul, Miok Pak \& Raffaella Zanuttini. 2019. The speaker-addressee relation at the syntaxsemantics interface. Language 95(1). 1-36. https://doi.org/10.1353/lan.2019.0008.

Potts, Christopher. 2007. The expressive dimension. Theoretical linguistics 33(2). 165-198. https://doi.org/10.1515/TL.2007.011.

Potts, Christopher \& Shigeto Kawahara. 2004. Japanese honorifics as emotive definite descriptions. Semantics and Linguistic Theory (SALT) 14. 253-270. https://doi.org/10.3765/salt.v14i0.2917.

Rackowski, Andrea \& Norvin Richards. 2005. Phase edge and extraction: A Tagalog case study. Linguistic Inquiry 36(4). 565-599. https://doi.org/10.1162/002438905774464368.

Riedel, Kristina. 2009. The syntax of object marking in Sambaa: A comparative Bantu perspective. Utrecht: LOT. https://hdl.handle.net/1887/14502.

Rizzi, Luigi. 2013. Locality. Lingua 130. 169-186. https://doi.org/10.1016/j.lingua.2012.12.002.

Sudo, Yasutada. 2012. On the semantics of phi features on pronouns. Cambridge, MA: MIT dissertation.

Toribio, Almeida Jacqueline. 1990. Specifier-head agreement in Japanese. West Coast Conference on Formal Linguistics (WCCFL) 9. 535-548

Watanabe, Narumi, Elin McCready \& Daisuke Bekki. 2014. Japanese honorification: Compositionality and expressivity. Proceedings of FAJL 7.

Wechsler, Stephen \& Larisa Zlatić. 2000. A theory of agreement and its application to serbocroatian. Language 76(4). 799-832. https://doi.org/10.2307/417200. 